\title{
CES
}

COOPERATIVISMO E ECONOMÍA SOCIAL

Núm. 43 (2020-2021), páxs. 279-285

ISSN: 2660-6348

\section{RÉGIMEN DE RESPONSABILIDAD DE LOS MIEMBROS DEL CONSEJO RECTOR. (ANOTACIÓN A LA SENTENCIA DE LA AUDIENCIA PROVINCIAL DE ZAMORA DE 17 DE MARZO DE 2020)}

\begin{abstract}
LIABILITY REGIME OF MEMBERS OF THE GOVERNING COUNCIL. (ANNOTATION TO THE JUDGEMENT OF THE COURT OF APPEAL OF ZAMORA, MARCH 17 2020)
\end{abstract}

Sinesio Novo FernándeZ*

Letrado de la Administración de Justicia del Juzgado de lo Social 3 de A Coruña. Dirección de correo electrónico: sinenovo@yahoo.es 



\section{SENTENCIA DE INSTANCIA}

T a mercantil ALMACENES CAÑAS S.A., presenta demanda para exigir la responsabilidad de los miembros del Consejo Rector de la cooperativa ORALCOOP SOC COOP, integrado a su vez por las cooperativas SOCIEDAD COOPERATIVA DEL CAMPO GLUS I, GEXVALL SOCIEDAD COOPERATIVA y A.P.P. TIERRAS DE CASTILLA Y LEÓN SOCIEDAD COOPERATIVA. La actora celebró un contrato de compraventa de distintas variedades de semillas de patata con ORALCOOP SOC COOP. y entregó el producto en los almacenes de una de las sociedades miembro del Consejo Rector de la compradora, en particular en los pertenecientes a SOCIEDAD COOPERATIVA DEL CAMPO GLUS I. A continuación, la mercancía fue revendida a otra de las sociedades integrantes del Consejo Rector, ante lo que la demandante alega que se trata de una autocontratación fraudulenta, puesto que ORALCOOP SOC COOP no destinó el importe cobrado al pago de la deuda contraída frente a ella. ALMACENES CAÑAS S.A. presentó demanda de reclamación del impago de la compraventa y, una vez firme la sentencia de condena, la correspondiente demanda de ejecución. La fase de apremio consecuente no pudo, no obstante, alcanzar la satisfacción de la acreedora, toda vez que fueron retirados los fondos de la sociedad ejecutada, esta abandonó el local donde ejercía su actividad y en la averiguación de bienes practicada figura la paralización e inactividad de la misma.

Por todo lo anterior, la mercantil acreedora ejercita la acción individual de responsabilidad de los miembros del Consejo Rector de la deudora por actos u omisiones de los administradores que lesionan los intereses de aquella, prevista en los artículos 236 y 241 LSC, y, de forma subsidiaria, la acción por responsabilidad solidaria de los administradores prevista en el artículo 367 del mismo texto legal, por incumplimiento de convocar en el plazo de dos meses la junta general para que adopte, en su caso, el acuerdo de disolución, así como de los administradores que no soliciten la disolución judicial o, si procediere, el concurso de la sociedad, en el plazo de dos meses a contar desde la fecha prevista para la celebración de la junta, cuando ésta no se haya constituido, o desde el día de la junta, cuando el acuerdo hubiera sido contrario a la disolución.

La causa de pedir es idéntica para ambas acciones. La demanda identifica como conducta de los administradores origen de su responsabilidad:

- la falta de diligencia en la gestión y administración, al efectuar pedidos en el año 2011 con ánimo de beneficio ilícito y aparentando una solvencia ficticia. 
- las mercancías vendidas por la actora fueron rápidamente transmitidas y el precio obtenido se aplicó a fines distintos de los de pagar la primera enajenación.

- endeudamiento progresivo y coetáneo de la sociedad compradora que desembocó en situación de insolvencia y vaciamiento patrimonial por haber ocultado o distraído sus activos.

- dejación de las funciones elementales de administración y gestión social que hicieron desaparecer la empresa.

- paralización de los órganos de administración y conclusión de hecho de la empresa, que hizo imposible la realización del fin social.

- incumplimiento de la obligación legal de nivelar el patrimonio y capital social en situación de pérdidas graves o, en su defecto, disolver y liquidar ordenadamente el patrimonio social.

- incumplimiento de las obligaciones impuestas.

De las tres codemandadas, únicamente se personó SOCIEDAD COOPERATIVA DEL CAMPO GLUS I. Su oposición se fundamentó en que las compras no se realizaron con ánimo ilícito o fraudulento y a sabiendas de que no se podría pagar. También alegó que la insolvencia de ORALCOOP SOC COOP no fue provocada por su conducta, sino por el impago de otros clientes, y aporta prueba documental para acreditar que estaba activa en fechas próximas a la compraventa que originó su deuda. Finalmente, manifiesta que la cooperativa deudora no tuvo inmuebles a su nombre sino créditos impagados, por lo que no hubo vaciamiento u ocultación de patrimonio social.

La sentencia de primera instancia descarta la acción ejercitada de forma subsidiaria, toda vez que diversa doctrina jurisprudencial considera que no es aplicable a las cooperativas la responsabilidad de los administradores prevista en el artículo 367 de la Ley de Sociedades de Capital. Por lo que respecta a la acción individual reconocida en los artículos 236 y 241 LSC, la sentencia recuerda los requisitos exigidos por jurisprudencia consolidada para poder apreciar responsabilidad de los miembros del Consejo Rector: comportamiento activo o pasivo de los administradores, imputable al órgano de administración, que sea antijurídico por contrario a la ley, a los estatutos o no respetar los estándares de diligencia exigible al empresario, que cause un daño directo a terceros con dolo, conducta abusiva o gravemente negligente.

La actora concreta las causas de responsabilidad de las demandadas en dos conductas: una posible autocontratación fraudulenta con una de las cooperativas que componían el Consejo Rector de la cooperativa deudora y la inactividad de dicho órgano para reflotar la cooperativa o solicitar el concurso. En cuanto a la primera, la sentencia no considera probado que el precio de la reventa pasara a integrar el patrimonio de SOCIEDAD COOPERATIVA DEL CAMPO GLUS I sin abonar 
contraprestación a la revendedora para que esta lo hubiera destinado al pago de la vendedora. En el mismo sentido, tampoco considera probado que la cooperativa compradora tuviera intención en el momento de la compra de no pagar el precio, toda vez que acredita documentalmente que esa época se encontraba operando normalmente. Por lo que respecta a la posible responsabilidad por ausencia de liquidación ordenada de la cooperativa, ante la ya comentada inaplicación del artículo 367 LSC, la sentencia trata de incardinar dicha conducta en el art 241 del mismo texto legal. La jurisprudencia del T.S. exige probar no sólo que el administrador no convocó la junta general, sino que de haberse liquidado correctamente la sociedad, el acreedor habría cobrado total o parcialmente su crédito. La sentencia concluye que esta última circunstancia no ha sido probada.

\section{SENTENCIA DE APELACIÓN}

La mercantil demandante recurre en apelación, si bien se muestra conforme con la inaplicación a las cooperativas de la acción por responsabilidad solidaria de los administradores por incumplimiento de la obligación legal de convocar en el plazo de dos meses la Junta General para que adopte, en su caso, el acuerdo de disolución de la cooperativa por concurrir causa legal. El recurso tiene por objeto, por tanto, la acción de responsabilidad individual de los miembros del Consejo Rector. De forma semejante a lo expuesto en la demanda, el escrito de recurso reitera que la sociedad cooperativa compradora realizó una liquidación clandestina del activo social y ya en situación de crisis convino con la demandante una compraventa de mercaderías que fueron inmediatamente revendidas a una de las cooperativas que formaban parte del Consejo Rector de la primera. Las mercancías desaparecieron y el precio de la reventa no se destinó al pago de la primera compraventa. La sentencia dictada por la Audiencia Provincial de Zamora concluye que el hecho de revender las mercaderías a una cooperativa tercera, pese a que sea miembro del Consejo Rector de la compradora, no entraña fraude alguno si al comprar las mercaderías existía intención de pagarlas a la vendedora, acreditada con la capacidad económica de la compradora. Los datos contables aportados al procedimiento, que son los mismos de los que disponían los administradores en el momento de la firma de la compraventa, demuestran dicha capacidad.

Por otro lado, tanto el extracto de las cuentas bancarias como la prueba documental aportada con el escrito de contestación a la demanda, revelan actividad económica suficiente para inferir racionalmente que la compraventa no estaba presidida por la intención de la compradora de defraudar a la contraparte.

Así las cosas, la sentencia de apelación declara que no se puede concluir que en la fecha de concertarse el contrato de compraventa la cooperativa compradora hubiera tenido intención de no pagar el importe convenido, pues disponía de capacidad económica suficiente para hacer frente a la deuda y tenía actividad económica. 
El recurrente también denuncia como ilícito orgánico susceptible de generar responsabilidad individual de los miembros del Consejo Rector el cierre de hecho de la empresa sin la práctica de operaciones de liquidación y la distracción de activos. Para que surja dicha responsabilidad ha de probarse una relación de causalidad entre la conducta y el impago de la deuda. La sentencia no llega a tal conclusión, puesto que no se constató la existencia de concretos activos cuya realización hubiera permitido abonar total o parcialmente la deuda. En la misma línea, tampoco se acreditó que de haberse realizado la correcta disolución y liquidación hubiera sido posible la satisfacción del acreedor.

\section{LA RESPONSABILIDAD DE LOS ADMINISTRADORES DE LAS SOCIEDADES COOPERATIVAS.}

Tanto la Ley de Cooperativas de Castilla y León como la ley estatal sobre la materia, en su condición de ley supletoria, efectúan remisión al régimen de responsabilidad de los administradores de otras sociedades mercantiles. Así las cosas, para que los administradores, o en este caso los miembros del Consejo Rector de la cooperativa compradora, se hagan responsables de la deuda, la Ley de Sociedades de Capital nos ofrece en principio dos posibilidades que requieren, no obstante, distintos presupuestos. La primera de ellas sería el ejercicio de la acción individual de responsabilidad, recogida en el artículo 241 LSC. Ahora bien, para que se pueda declarar la responsabilidad individual de las cooperativas miembros del Consejo Rector que nos ocupa es necesario el cumplimiento de una serie de requisitos recogidos de forma unánime por la doctrina y que responden al esquema clásico de la responsabilidad extracontractual por culpa. Nos estamos refiriendo a:

- existencia de comportamiento activo o pasivo.

- comportamiento imputable en este caso a las cooperativas integrantes del Consejo Rector de la sociedad deudora.

- comportamiento antijurídico.

- existencia de una relación de causalidad entre el comportamiento y el daño. Es en este punto en donde nos encontramos con el principal obstáculo para el éxito de la acción de responsabilidad individual por daños. Es difícil establecer y probar un nexo causal entre el comportamiento de las demandadas y el impago de la deuda, como finalmente ha sucedido tanto en la sentencia de primera instancia como en la de apelación.

Por todo lo anterior, en un principio sería interesante desde el punto de vista de la actora explorar la segunda vía prevista en LSC, entre otros motivos porque no requiere dicho nexo causal entre una acción y un daño. El artículo 367 prevé la responsabilidad solidaria de los administradores, por incumplimiento del deber de promover la disolución, de las obligaciones sociales posteriores al acaecimiento 
de la causa legal de disolución. El Tribunal Supremo también ha perfilado claramente los presupuestos para que pueda exigirse esta responsabilidad:

- concurrencia de alguna causa de disolución de la sociedad.

- omisión por el administrador del deber de convocar en el plazo de dos meses la junta general para que adopte, en su caso, el acuerdo de disolución, así como de solicitar la disolución judicial o, si procediere, el concurso de la sociedad, en el plazo de dos meses a contar desde la fecha prevista para la celebración de la junta, cuando ésta no se haya constituido, o desde el día de la junta, cuando el acuerdo hubiera sido contrario a la disolución.

- imputabilidad al administrador de la conducta pasiva.

- inexistencia de causa justificadora de la omisión.

En todo caso, como ha señalado la sentencia de primera instancia y ha quedado fuera del objeto del recurso, el Tribunal Supremo ha rechazado la aplicación de esta responsabilidad a los miembros del Consejo Rector de las sociedades cooperativas. Según la sentencia de la Sala de lo Civil, Sección $1^{\text {a }}$, de 10 de marzo de 2015, "ni en la legislación estatal ni en la autonómica de Castilla-León de cooperativas, según se ha visto, existe una responsabilidad de los miembros del Consejo Rector equiparable a la responsabilidad de los administradores de sociedades de capital para el supuesto de que no se convoque la Junta de socios de existir causa de disolución. Por ello, no cabe, a falta de una remisión legal clara y específica, realizar una aplicación extensiva del régimen de responsabilidad previsto en el artículo 367 LSC a otras formas asociativas, salvo que la ley autonómica así lo hubiera previsto expresamente". 